\title{
NEGOEIOS MUSICALES
}

¿SE PUEDE VIVIR DEL ARTE EN EL PERÚ?

\section{GINO Fopplano}

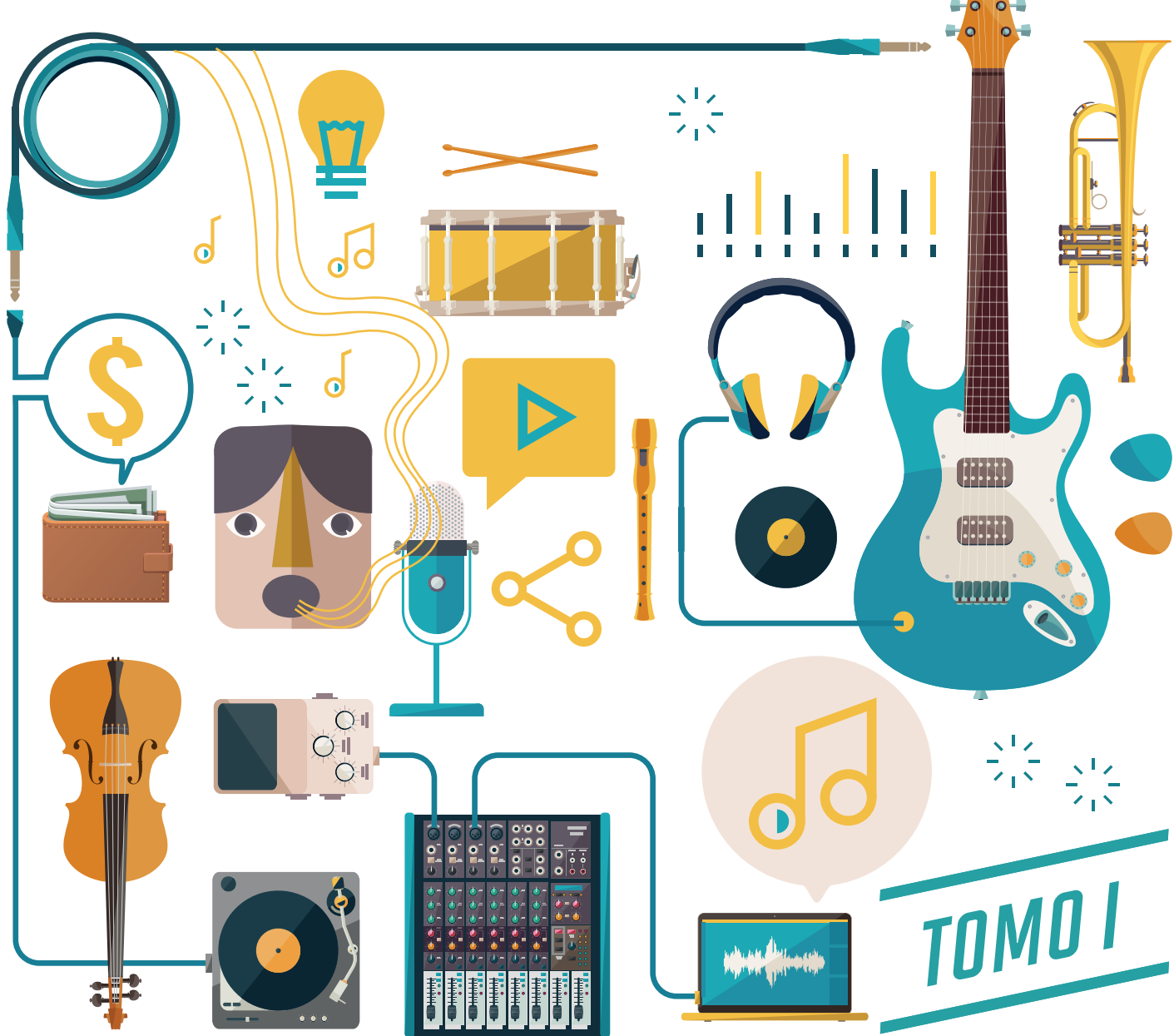



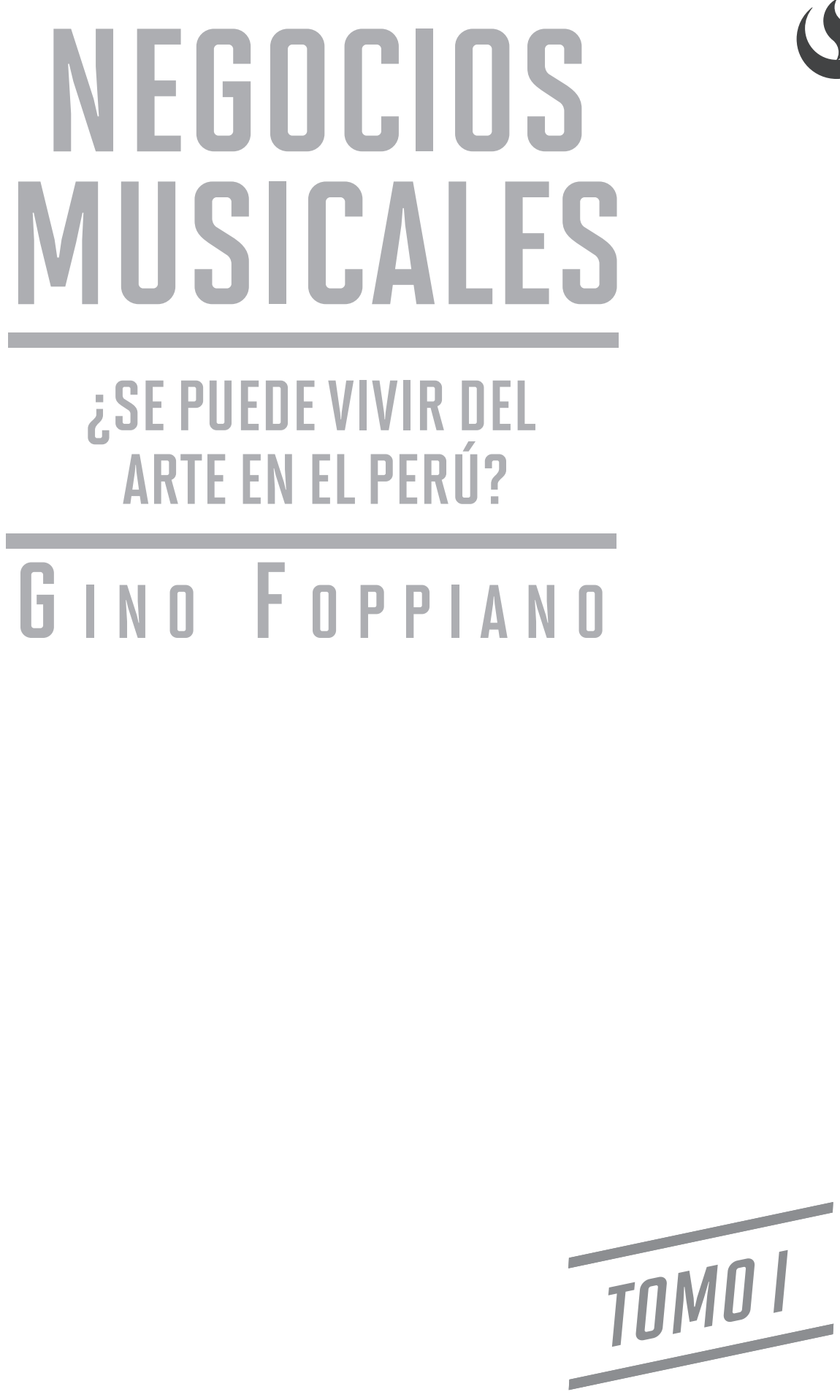

Lima, julio de 2016

Universidad Peruana de Ciencias Aplicadas 
(C) Universidad Peruana de Ciencias Aplicadas (UPC)

Primera publicación: julio de 2016

Impreso en el Perú - Printed in Peru

Autor: Gino Foppiano

Edición: Diana Felix

Corrección de estilo: Jessica Vivanco

Diseño de cubierta: TALLER LOV S.A.

Diagramación: Diana Patrón Miñán / Christian Castañeda

Editor del proyecto editorial

Universidad Peruana de Ciencias Aplicadas S. A.C.

Av. Alonso de Molina 1611, Lima 33 (Perú)

Teléf: 313-3333

www.upc.edu.pe

Primera edición: julio de 2016

Tiraje: 1000 ejemplares

Este libro se terminó de imprimir en el mes de julio de 2016, en los talleres gráficos de Gráfica Biblos, Jr. Morococha 152, Surquillo, Lima - Perú.

\section{Universidad Peruana de Ciencias Aplicadas (UPC) \\ Centro de Información}

\section{Foppiano, Gino}

Negocios Musicales: ¿se puede vivir del arte en el Perú? / Gino Foppiano.-- Primera edición.-Lima: Editorial UPC, 2016.

ISBN 0.C. (Obra Completa): 978-612.318-053-9

ISBN: 978-612.318-054-6

1. Industria musical 2. Música folclórica 3. Radio 4. Educación musical 5. Orquesta

6. Compositores 7. Legislación 8. Perú

780.0338 FOPP

Hecho el Depósito Legal en la Biblioteca Nacional del Perú nro. 2016-08517

Registro de Proyecto Editorial en la Biblioteca Nacional del Perú nro. 3150-1021600550

Todos los derechos reservados. Esta publicación no puede ser reproducida, ni en todo ni en parte, ni registrada en o transmitida por un sistema de recuperación de información, en ninguna forma ni por ningún medio, sea mecánico, fotoquímico, electrónico, magnético, electroóptico, por fotocopia o cualquier otro, sin el permiso previo, por escrito, de la editorial.

El contenido de este libro es responsabilidad del autor y no refleja necesariamente la opinión de los editores. 


\section{Contenido}

Agradecimiento

Presentación

Prólogo

Introducción

PRIMERA PARTE. Aspectos introductorios sobre la administración de negocios musicales

Capítulo 1. La administración y la organización en los negocios musicales

1.1 La organización como concepto administrativo

1.2 Organización de los negocios musicales

1.3 Características de los administradores musicales

1.4 Análisis de los cambios en el tiempo

1.5 La cadena de valor entre la industria musical y su evolución en el tiempo

Capítulo 2. Las oportunidades de trabajo y de negocio dentro del quehacer musical

2.1 Aspectos generales

2.2 Revisión de actividades relacionadas con los negocios musicales

2.3 Nuevos campos dentro del quehacer musical

2.4 La educación musical en el Perú 
Capítulo 3. La administración de la tecnología, los nuevos medios digitales y los negocios musicales

3.1 Una visión general de los negocios musicales digitales

3.2 Influencias de la tecnología en la organización

3.3 Tecnología en la vida diaria

3.4 Las redes sociales y la social media

3.5 Las redes sociales más importantes

SEGUNDA PARTE. Aspectos introductorios sobre la administración de negocios musicales

Capítulo 5. Manuel Garrido-Lecca, productor musical que traspasa fronteras 91

5.1 Descubriendo su camino musical

5.2 Nuevas y grandes oportunidades

5.3 Una visión distinta a la música peruana

5.4 Producción en acción 96

5.5 Organización a nivel de producción musical 96

5.6 Manuel y el mercado 98

5.7 Derechos de autor: opinión de un productor 100 
6.1 Su inicio en la música

6.2 Nuevos horizontes radiales

6.3 Renovando el mercado discográfico peruano: 11 y 6 y CD PERÚ

6.4 Total show, tercer nicho

6.5 Diferentes líneas para una producción de calidad

6.7 Los nuevos proyectos del Grupo 11 y 6

Capítulo 7. Cocodrilo Verde, honrando la vida a través de la música

7.1 Música para aficionados

7.2 Cocodrilo Verde, nueva etapa en la vida de Luisa

7.3 Noche de Aficionados

7.4 Servicio de calidad

7.5 Una buena opción entre muchas más

7.6 Inculcando el arte a más personas

7.7 Apoyando al arte en todo sentido

Capítulo 8. Miguel Molinari, gestor y promotor de una cultura musical sin límites

8.1 Sus inicios

8.2 Ingreso a la música de ópera y encuentro con Juan Diego Flórez

8.3 Logros, reconocimientos y actividades musicales

8.4 Principales actividades musicales

8.5 Sinfonía por el Perú 
8.7 Financiamiento de la organización

8.8 Relación con los teatros latinoamericanos

\section{Capítulo 9. Juan Alberto Mata, consultor de una industria} musical en crecimiento

9.1 Sus primeros pasos en la música

9.2 Ad Music Consulting, una MYPE relacionada con la música

9.3 Punto de vista relacionado con los negocios musicales

9.4 El marketing antiguo versus el marketing actual

9.5 El mundo de las plataformas digitales: ¿ventaja o desventaja?

Capítulo 10. El «Mono» Landavere, mente creativa que transmite emociones 147

10.1 Sus inicios como músico

10.2 Los jingles como negocio publicitario

$10.3 \mathrm{El}$ «Mono» en su etapa de músico

10.4 Reconocimientos y premios

10.5 Estructura organizacional y nuevo modelo de negocio adaptado a la tecnología

10.6 La madurez del artista y del productor de jingles

10.7 El marketing simple en las actividades musicales de Landavere

11.1 Su carrera en la música

11.2 Un nuevo rumbo musical 
11.4 Modelo de negocio en torno a la música

11.5 Otros rubros musicales

11.6 La organización de sus líneas de negocio

11.7 Su relación con la industria musical peruana

Capítulo 12. Rossy War y Alberto Mauri, la transformación de la música tropical

$\begin{array}{ll}\text { 12.1 Rossy War, su niñez y adolescencia } & 167\end{array}$

12.2 Inicios de Tito en el quehacer musical 168

12.3 Tito Mauri y su estadía en la empresa Infopesa 169

$\begin{array}{ll}\text { 12.4 Mauri se independiza } & 170\end{array}$

12.5 Rossy War y el inicio de su exitosa carrera 170

12.6 Aspectos empresariales y de marketing $\quad 174$

12.7 Plataformas digitales, discografía y piratería 175

$\begin{array}{ll}\text { 12.8 Modelo de negocio } & 176\end{array}$

$\begin{array}{ll}12.9 \text { Rossy en SONIEM } & 177\end{array}$

Capítulo 13. Manolo Barrios y la permanencia de Mar de Copas 179

$\begin{array}{ll}\text { 13.1 Sus inicios } & 179\end{array}$

13.2 Inicio de Mar de Copas 180

13.3 Una nueva forma de marketing 181

13.4 Banda independiente y nuevos rumbos 182

13.5 Nuevas formas de promoción 183

$\begin{array}{ll}\text { 13.6 De las redes a la radio } & 184\end{array}$

13.7 Sus principales líneas de negocio 184

13.8 Su organización 186

$\begin{array}{ll}\text { 13.9 Piratería e industria peruana } & 187\end{array}$ 
A mi esposa Alicia, a mis hijos Piero y Francesco. 



\section{Agradecimiento}

A los alumnos de la Escuela de Música de la Universidad Peruana de Ciencias Aplicadas A las 34 personalidades que aparecen en el libro

Brito Zamora

Carlos Sayán

Eduardo Buse

Escuela de Música de la Universidad Peruana de Ciencias Aplicadas

Editorial UPC

Iván Cock

Juan Alberto Mata

Marcia Morales

María Angélica Alcedo

Paula Bassallo

Rafael Arbulú 



\section{Presentación}

En el tomo I del libro Negocios Musicales, se presenta la administración de negocios musicales y su organización, así como la descripción de áreas relacionadas con el recurso humano dentro de la industria musical y la influencia de la tecnología en la era digital de los negocios musicales. El enfoque en esta primera parte, conserva una perspectiva tanto teórica como práctica, tomando en cuenta, aspectos aplicativos a la realidad peruana.

Este primer tomo introduce unos primeros ejemplos de artistas y empresarios de la música de gran trayectoria, que han podido incluirse, con el paso de los años, en la industria musical peruana. Se presentan los casos acerca del negocio musical de un productor musical, un ingeniero de sonido, un luthier, entre otros. 



\section{Prólogo}

Hablar de los negocios musicales en nuestro país lleva a que nos preguntemos cuáles son estos negocios y si en verdad existe una industria musical peruana, si el músico puede vivir de su arte, si el retorno por el esfuerzo, que implica componer, producir y tocar en vivo, vale la pena.

Este libro detalla los emprendimientos de diversos artistas y profesionales de la industria musical. Desde sellos discográficos, luthiers, gestores culturales, espacios de difusión musical, productores, ingenieros de sonidos, orquestas, bandas y solistas, se presentan en detalle los aspectos que los hacen exitosos y que, además, son ejemplo de gestión que deberán seguir quienes deseen incursionar en el mundo del arte y entretenimiento.

Gino Foppiano, mi profesor, maestro de mis alumnos y profesor en la Escuela de Música de la UPC quiso, con este libro, demostrar que sí se puede vivir del arte, de la música; que es rentable, que existe una industria pequeña, pero pujante y en crecimiento, que quienes tomaron en serio este camino desarrollaron modelos de negocio exitosos así no supieran nada de temas administrativos, contables o de gestión empresarial.

Gino Foppiano muestra, en este libro, cómo estos emprendimientos lograron forjarse y volverse exitosos. Brinda un orden muy específico, desde su óptica de administrador y especialista en gestión, a cada uno de los casos de éxito presentados.

Gino fue mi colega, mi maestro y el de varias generaciones. Con su cátedra en la Escuela de Música de la UPC logró que muchos músicos entendieran la importancia de verse como empresarios, gerentes, administradores de su arte y su talento. Entendió la importancia de inculcar en los artistas las claves del éxito empresarial, el orden que toda idea tiene que tener para sobrevivir y salir adelante.

Gino trabajó dos años en este proyecto y no lo vio nacer. Lo dejó listo y entregó la posta. Nos toca a nosotros, sus colegas y alumnos, tomar lo que deja como enseñanza en estas páginas. Es nuestro deber como músicos, que deseamos que nuestra industria crezca y se fortalezca, reconocer en su legado la ruta trazada.

\section{Carlos Sayán Rojas}

Director de la Escuela de Música Universidad Peruana de Ciencias Aplicadas 



\section{Introducción}

Este libro tiene como objetivo principal abordar el tema de los negocios musicales desde una perspectiva poco tratada en el Perú. Mi intención es mostrar las actividades y el quehacer en general de aquellas personas, en algunos casos ligadas a instituciones, que han tenido éxito en el ámbito musical. El éxito no es solamente económico, también se puede medir a partir del logro de los objetivos trazados. En ese sentido, es necesario mencionar que en esta publicación se presentan los casos de un grupo de personajes representativos de las diversas actividades relacionadas con los negocios musicales.

La idea de escribir este libro surgió cuando comencé a dictar clases en la Escuela de Música de la Universidad Peruana de Ciencias Aplicadas (UPC). Después de 35 años de experiencia como docente, ha motivado mi quehacer profesional encontrar estudiantes músicos, cantantes y compositores interesados en la producción musical o alumnos que simplemente piensan incursionar en negocios musicales. Los estudiantes, con sus preguntas y cuestionamientos sobre las enseñanzas impartidas, me acercaron a esta nueva generación interesada en la música. Ellos consideran que el desarrollo de sus actividades musicales tiene que generarles beneficios económicos, y no necesariamente para hacerse ricos —aunque ¿por qué no?-; muchos se sumergen en la música porque es el mundo donde quieren vivir.

Al respecto, «hacer hacer» pareciera una expresión errada desde el punto de vista gramatical. «Hacer hacer» es administrar, y esta es una actividad que le interesa a muchas personas dentro del medio musical. Recalco que los jóvenes no necesariamente ven en el negocio musical un fin lucrativo, para ellos es un modo de vida, pues significa vivir de lo que les gusta. También hay algunos que buscan trascender con su obra; otros quieren fama. Para todos ellos va dirigido este libro, el cual fue escrito en colaboración de un maravilloso equipo liderado por María Angélica Alcedo, quien contó con el apoyo de Marcia Morales y Paula Basallo. Sin el apoyo de las tres, la realización del libro no hubiera sido una realidad. La finalidad de esta publicación es mostrar casos de empresarios que apostaron por el negocio musical y que destacan por su iniciativa, ímpetu, perseverancia, arte y calidad musical o por su sostenibilidad.

El libro pretende describir casos de negocios musicales peruanos o desarrollados por compatriotas nuestros que hayan trascendido y sirvan como ejemplo, de esta 
manera se le brindará al lector información que lo ayude a tomar decisiones con más conocimiento sobre el tema.

Esta obra se divide en dos tomos. La primera parte del Tomo I se enfoca en la actividad musical relacionada con la administración de empresas. En ella se revisa la información teórica y se analizan la organización, las funciones de los profesionales involucrados y la nueva influencia de la tecnología en los negocios musicales. La segunda parte de este tomo, en cambio, presenta 11 historias, narradas a modo de crónica, sobre la administración de los negocios y los logros en la industria del entretenimiento de personajes del ámbito musical peruano. Entre ellos encontramos a un luthier, productores musicales, gestores culturales, cantantes, entre otros.

El tomo II presenta tres partes. En la primera parte continúan las crónicas sobre personajes exitosos del ámbito musical y sus modelos de negocio, pero esta vez el enfoque es sobre las funciones de los servicios (disk jockey, iluminación, sonido para eventos), los educadores de la música, los grupos radiales y los programas de entretenimiento musical en televisión. En la segunda parte se explican los casos de innovación musical de orquestas, cantautores de música folclórica moderna, compositores y casos de jóvenes emprendedores en el negocio de la música. La tercera parte de este tomo presenta el marco legal, sobre todo el relacionado con derechos de autor, producción musical, leyes que intervienen en el quehacer musical, opciones de financiamiento y nuevas tendencias de marketing en la industria musical.

El libro va dirigido a los estudiantes de negocios musicales y músicos. También a los estudiantes de ciencias empresariales y carreras relacionadas que están interesados en el tema musical desde cualquier ámbito. Además, considero que será útil para personas que no aborden el tema de negocios musicales desde el punto de vista académico, sino para empresarios musicales, músicos, directores de orquesta, compositores y, en general, personas interesadas en el negocio musical.

Mi equipo y yo consideramos que esta publicación será útil porque es uno de los primeros libros en el Perú que abordan el tema musical, el cual cada vez tiene más relevancia en la realidad peruana. Los negocios musicales son más numerosos y competitivos en la actualidad; por ello, es necesario ser cada vez más eficiente y eficaz. En ese sentido, intento, desde mi humilde posición, mostrar una visión de las ciencias administrativas aplicadas a los negocios musicales. 


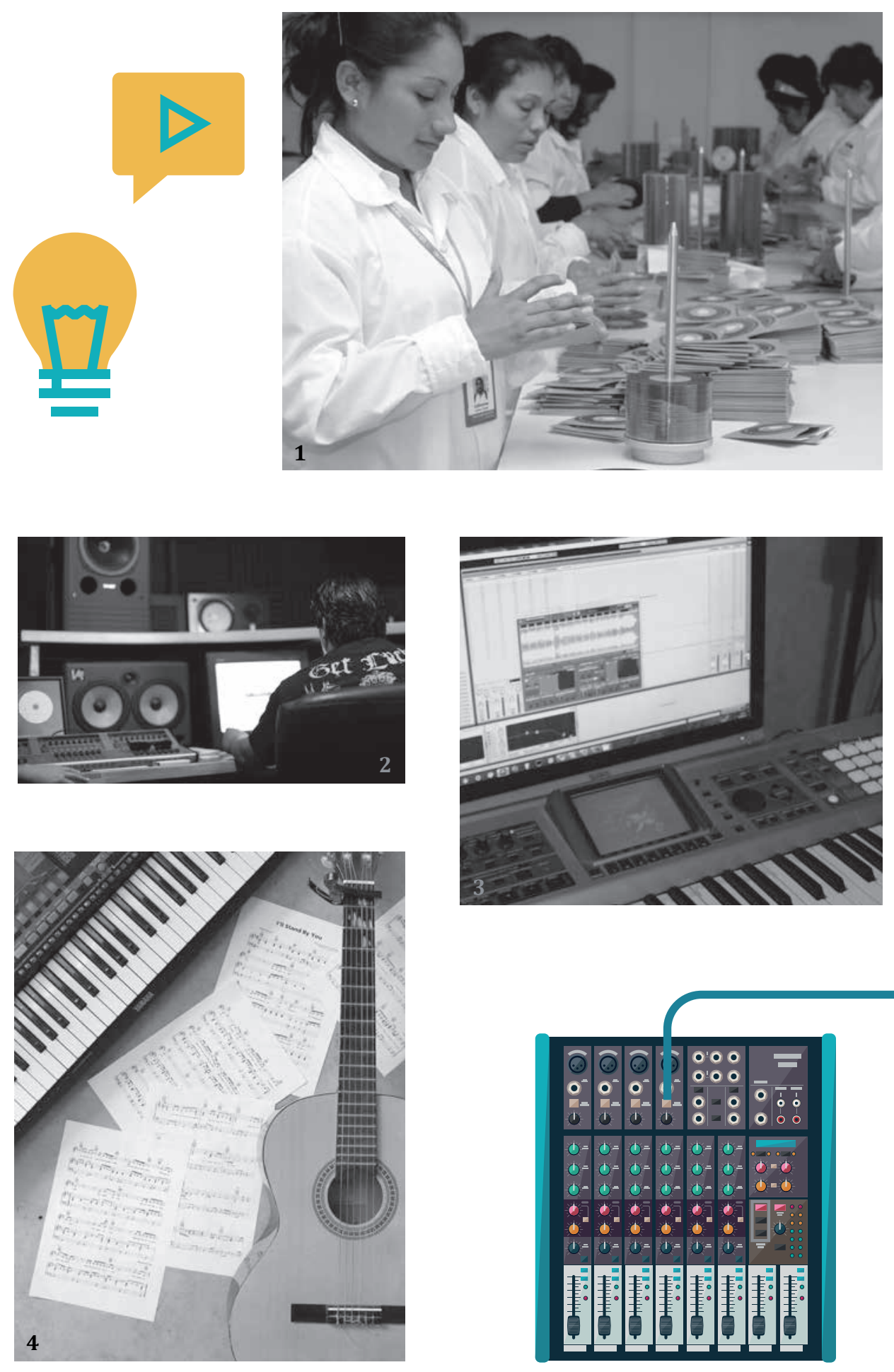

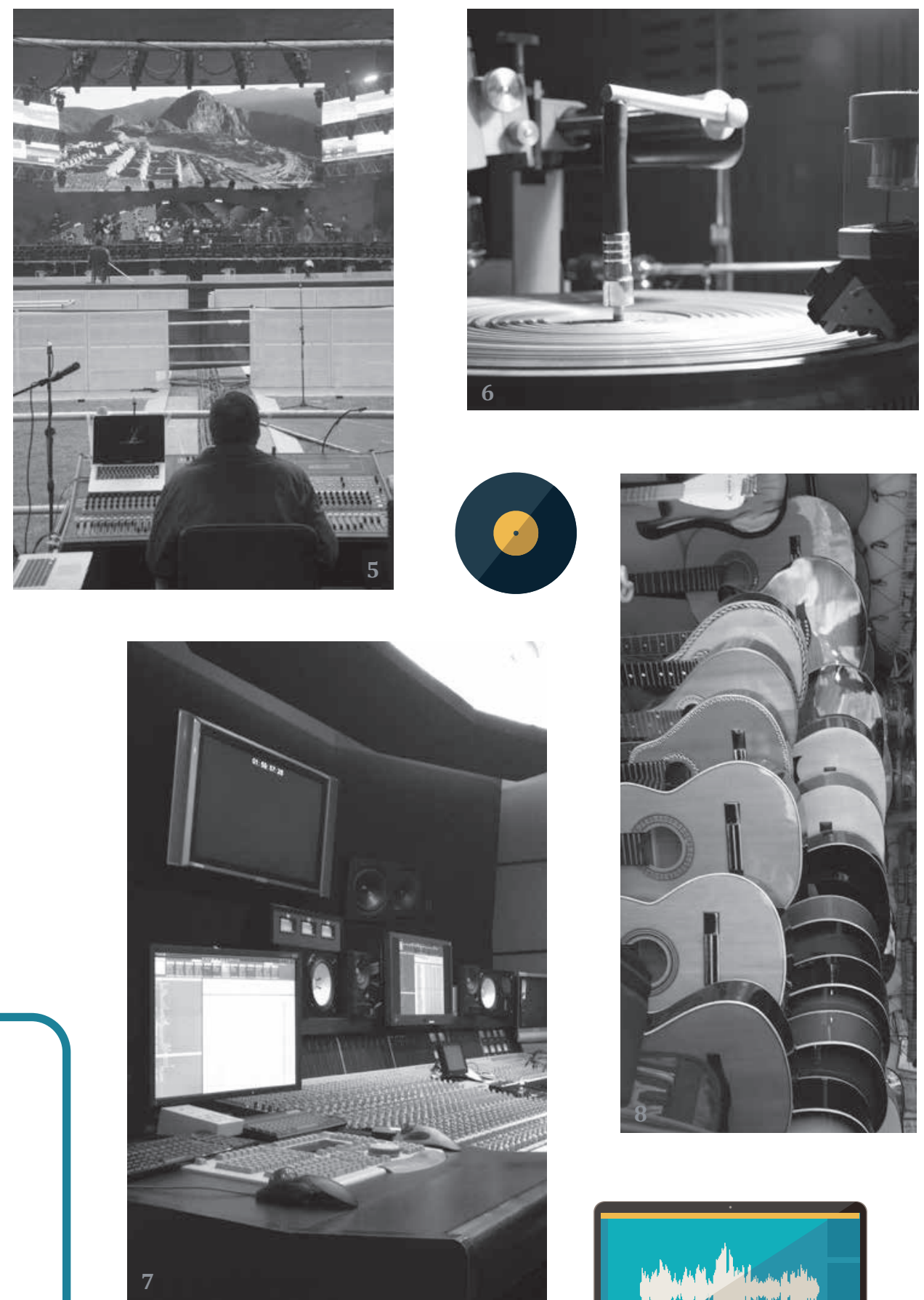
1. Fuente: de Freddy Padilla

2. Wikimedia commons, Mark Sebastian

3. Wikimedia commons, Tim Sherman-Chase

4. Wikimedia commons, Márcio Binow da Silva

5. Fuente: Archivo personal de Rafo Arbulu

6. Wikimedia commons, Jaco Ten

7. Wikimedia commons, Autobahn Two

8. Fuente: Foto de Gino Foppiano 


\section{PRIMERA PARTE \\ Aspectos introductorios sobre la administración de negocios musicales}





\section{Capítulo 1. La administración y la organización en los negocios musicales}

Los negocios musicales son como cualquier empresa, pero con la particularidad de que el negocio principal o core business ${ }^{1}$ gira en torno a la música. En el Perú como en el mundo, los músicos y las personas naturales o jurídicas (empresas o instituciones) que participan en los negocios musicales deben generar excedentes económicos, no necesariamente con intenciones de lucro, sino para la satisfacción de las necesidades de las personas naturales de cualquier índole o para la supervivencia y crecimiento de las organizaciones en general.

Por ejemplo, una organización sin fines de lucro, como una institución que crea, opera y mantiene una orquesta sinfónica regional, también necesita cumplir con requerimientos para mantenerse en el tiempo, porque los instrumentos musicales no son eternos y, en general, toda institución tiende a crecer y tener sostenibilidad. En el caso de una empresa, como una productora, creada para brindar conciertos de artistas musicales nacionales y extranjeros más renombrados, deberá generar utilidades (excedentes económicos) para que la misma empresa o los dueños de la organización justifiquen su inversión. De esa manera se obtiene una rentabilidad después de haber cumplido con todas sus obligaciones laborales: pago de proveedores e impuestos y todos los gastos que demande el negocio.

Para generar excedentes económicos, deben valerse de la teoría y praxis de la administración de empresas que, como ciencia, recibe aportes del marketing, la tecnología, la política, la psicología, los métodos cuantitativos, entre otros, en el que su objeto de estudio es la organización ${ }^{2}$.

1 Término anglosajón que se refiere al giro del negocio o su competencia clave. Es lo que genera valor en el negocio.

2 Cfr. Valeriano 2008: 9. 
La actividad musical relacionada con los negocios musicales puede generar bienes o servicios, que pueden ser vendidos, comprados, comercializados y, en general, ser sujetos a transacciones comerciales ${ }^{3}$. Como se notará, es importante administrar el negocio musical para que genere beneficios, ya sea en entidades con fines de lucro u otras.

Se dice que la administración es considerada una ciencia y técnica ${ }^{4}$, pero también es un arte ${ }^{5}$ :

«Como arte, la administración se caracteriza por contar con virtud, disposición y personalidad para construir un escenario favorable en una organización de seres humanos con atributos variados y complejos. La administración rescata la necesidad de usar la creatividad en la solución de problemas que impiden el avance de las estrategias y objetivos propuestos» (Valeriano 2008: 9).

La creatividad y el arte son parte misma del negocio musical. Como se verá en este libro, los empresarios, emprendedores y artistas utilizan los últimos adelantos de las ciencias administrativas, llamada también administración, de la mano con la creatividad.

Jiménez Nieto considera que la administración es una ciencia sincrética, una ciencia de segundo grado que fusiona en sí a las ciencias sociales básicas: la economía, el derecho, la ciencia política y la sociología, de las que toma los conceptos básicos relacionados con los grupos intermedios ${ }^{6}$. A esto se agrega que algunos autores también consideran a las matemáticas, estadística y psicología como otras ciencias que aportan al objeto de la administración ${ }^{7}$.

3 Cfr. Byrne 2012: 221.

4 Cfr. Bunge 1993.

5 Cfr. Chiavenato 2014: 9.

6 Cfr. Jiménez 1978: 99.

7 Cfr. Valeriano 2008: 9. 


\subsection{LA ORGANIZACIÓN COMO CONCEPTO ADMINISTRATIVO}

La tarea principal de los administradores, no solo del área musical, sino, en general, es hacer que las personas desarrollen su trabajo con eficiencia y eficacia. El avance tecnológico y el desarrollo de las ciencias por sí mismo no producirán efecto si es que la organización no es manejada en forma que los seres humanos logren alcanzar los objetivos comunes de la organización. La administración es un proceso que se basa en planear, estructurar y controlar el uso de los recursos para lograr dichos objetivos ${ }^{8}$.

La organización, según el autor Idalberto Chiavenato, es una entidad social compuesta por personas y recursos, estructurada y dirigida deliberadamente para alcanzar un objetivo común, el cual, según Child, se debe basar en la generación de «una buena organización»; para ello, se deben considerar tres aspectos fundamentales en su sistema: una estructura básica que describe la organización formal, llámese organigrama; la explicación de lo que se espera de cada uno de los integrantes de la organización; y cómo definir claramente los mecanismos de decisión para que la organización funcione ${ }^{9}$. Opinamos que esta es una buena descripción de los aspectos formales de una organización, pero a esto habría que agregar la parte informal que en los negocios musicales es muy importante: la cultura organizacional de la empresa y las relaciones informales entre los integrantes.

La cultura organizacional, aspecto informal de la empresa, está conformada por las creencias, los valores, las maneras de actuar y hasta formas de vestirse en la empresa. Para aclarar este apartado, bastará que el lector se imagine un banco en el que su estructura formal organizacional y las relaciones entre los miembros de la organización son verticales y su organigrama presenta muchos niveles. La vestimenta, en estos casos, proyecta conservadurismo, normas estrictas, sobriedad y seriedad. En el caso de una empresa musical — productora de jingles o un estudio de grabación—, las relaciones son mucho más horizontales; por la toma de decisiones es más democrática, la vestimenta suele ser más casual y adaptada a los gastos y preferencias de cada persona que toma parte de la organización.

El organigrama de una empresa, que es la expresión formal y gráfica de sus relaciones de poder, es la representación en forma intuitiva y concreta de los cargos y puestos de trabajo en donde se indican relaciones de autoridad, responsabilidad, coordinación, entre los aspectos principales ${ }^{10}$.

\footnotetext{
8 Cfr. Chiavenato 2014: 8.

$9 \quad$ Cfr. Child 1989: 16-17.

10 Cfr. Foppiano 2013: 204.
} 
La organización de negocios musicales presenta aspectos particulares relacionados con las principales funciones que ejerce, las cuales nombraremos a continuación ${ }^{11}$ :

- Conseguir fondos.

- Producir bienes o servicios relacionados con la música, tomando en cuenta toda la cadena de valor de los negocios musicales.

- Distribuir bienes y servicios musicales a través de los canales tradicionales por los que brinda la tecnología digital.

- Desarrollar las estrategias de marketing adecuadas para el negocio, de acuerdo con las características del producto, mercado objetivo, envergadura del negocio, aspectos promocionales, entre otros.

- Manejar el flujo de efectivo de los fondos que se necesitarán en el negocio, que está relacionado con la realización de giras, elaboración de grabaciones, eventos promocionales y otros aspectos. El flujo de efectivo deberá ser manejado de manera que no solamente se planifique la consecución de fondos, sino que se utilice en el momento conveniente y en los montos apropiados para que el negocio tenga la liquidez requerida.

- Si es el caso, asesorar y guiar a los artistas, compositores o productores - los managers y las compañías discográficas lo hacen normalmente- para alcanzar el éxito comercial y financiero.

- Manejar la contabilidad y finanzas, pago de impuestos y actividades relacionadas con los aspectos económicos y financieros de los negocios musicales.

\subsection{ORGANIZACIÓN DE LOS NEGOCIOS MUSICALES}

En esta parte, analizaremos la organización de las empresas musicales en el Perú. En la práctica, presenta las siguientes características:

\subsubsection{Organización por proyectos}

Es muy útil para los productores musicales y las empresas administradoras de eventos relacionados con la música. Las organizaciones que gestionan proyectos musicales y,

11 Cfr. Byrne 2012: 222-223. 
en general, culturales, son aquellas en las que se busca ser sumamente flexible y capaz de reaccionar ante los cambios del mercado ${ }^{12}$, importante para las estructuras contemporáneas en las que se requiere el personal necesario y calificado para cada situación determinada. Tal es el caso de una productora musical, encargada de realizar eventos, pues requiere de ingenieros de sonido, personal de producción, promotores, entre otros profesionales, con características específicas relacionadas con la propuesta musical, el número de espectadores, el mercado objetivo y el tipo de local, entre los aspectos principales. Por otro lado, si analizamos el caso de un evento en un estadio de 30000 personas de un cantante, como Elton John, la producción de estreno no será igual al de un guitarrista de música de jazz en un local para 100 personas con precios elevados. Cada uno de ellos requiere de diferentes tipos de especialistas en el manejo del evento musical; por lo tanto, la organización deberá ser diferente y adaptarse a cada situación.

Cabe señalar que la estructura organizacional por proyectos es la más usada en el campo de las industrias musicales. Al presentar características diversas de acuerdo al producto que se genera tanto en el ámbito de producción de eventos como en el de la industria discográfica — como ya se ha visto en el párrafo anterior-, se requerirán diferentes recursos humanos (cantidades, personal, tiempos, etcétera).

La administración define a este tipo de organización como sistemas intermitentes unitarios, ya que no se produce en línea, sino que cada uno de ellos se genera como un producto nuevo porque presenta características únicas y diferentes a otros productos generados. Actualmente, una rama de la administración de operaciones, que es la gerencia de proyectos, ha desarrollado toda una metodología y teoría sobre el particular. Inclusive, existe un organismo conocido como Project Management Institute Inc. que ha desarrollado la Guía de los Fundamentos para la Dirección de Proyectos, más conocida como el $\mathrm{PMBOK}^{\circledR}$, la cual sería recomendable usar para la administración de este tipo de negocios musicales.

1.2.2 En la organización de las grandes empresas, en su mayoría, tomando en cuenta el caso de sellos discográficos, corporaciones radiales y organizaciones empresariales con un mercado con demanda constante, la estructura organizacional podrá ser funcional, en el caso de las pequeñas empresas, y matricial, para las grandes y medianas, ya que es una estructura por proyectos más compleja. Podríamos citar el caso de un 
sello discográfico independiente de pequeña envergadura que produce y distribuye discos compactos, el cual necesita agrupar a todos los que se dedican a una actividad como el mercadeo, la producción discográfica en sí o la parte contable y financiera en su organización. Para ello, se debe aplicar el principio funcional o principio de la especialización de las funciones. En el caso de una empresa transnacional discográfica, que necesita responder a muchos productos a la vez, trabajará con una estructura estática funcional y una dinámica que podría ser por producto, por división de los productos, por motivos geográficos, por mercado. En estos casos se podría trabajar con una estructura matricial para responder a multiproductos o multimercados ${ }^{13}$. Este es el caso de las organizaciones que representan a empresas transnacionales, como Sony Music Entertainment o Warner Music Group.

1.2.3 La estructura matricial responde a la necesidad de organizaciones que, por su envergadura y las características multidisciplinarias de su administración, necesitan que el liderazgo sea potenciado por una estructura que trascienda en el tiempo, aunada a una organización que responda a las características del mercado, que es cambiante. Además del ejemplo anterior, podría plantearse el caso del Grupo 11 y $6^{14}$, que se explicará en el capítulo seis de esta publicación y que tiene una estructura permanente en el que se manejan las funciones principales de una institución financiera, de marketing, de producción, entre otras. También podría presentarse el mismo caso en una estructura desarrollada para cada uno de los proyectos discográficos, de manejo de artistas, de distribución y de promoción de productos musicales, entre otros.

1.2.4 La microempresa, en algunos casos, presenta estructuras organizacionales que apuntan a ser de tipo simple, en donde el dueño, el maestro o, en general, una persona con mucha experiencia, la lidera, y no existen muchos aspectos formales. Sin embargo, podrían también considerarse de tipo en trébol o adhocrático, en las que la estructura es poco formalizada por agrupar multidisciplinariamente a especialistas de diferentes propósitos específicos o tienen un orden horizontal casi total. Por lo que se presume que la organización, en estos casos, es de estructura horizontal, multidisciplinaria, ade-

13 Cfr. Foppiano 2013: 205-206.

14 Sello discográfico del cual se hará referencia en la segunda parte de este libro, al considerar el caso de Carlos Sánchez de la Puente. 
más, casi siempre con algunos rasgos de funcionalidad. Este tipo de organización se hace explícita en negocios como el del luthier Antonio Huamaní, la consultora de Juan Alberto Mata (AdMusic Consulting) — citados en este libro-y otros casos en los cuales el número de individuos en la organización no llega a más de 10 personas.

Los músicos que se administran a sí mismos, los consultores en cualquier aspecto de los negocios musicales, los compositores que no trabajan directamente con organizaciones y, en general, aquellos que trabajan como freelance ${ }^{15}$ son los casos más relacionados con este tipo de organización.

1.2.5 Las micro y pequeñas empresas, sobre todo las dirigidas a géneros populares, como la tecnocumbia, la música criolla y la música andina, entre otros, presentan estructuras organizacionales semiplanas, en las que el trabajo se convierte en un proceso con tercerización de servicios para ahorrar en la infraestructura humana y técnica, pero cada vez más especializadas en lo que se necesita ${ }^{16}$. En este caso se encuentran las MYPE que brindan servicios de alquiler de equipos de sonidos, salas de grabación, locales con seguridad, entre otros. En cuanto a las empresas relacionadas con el movimiento musical chichero ${ }^{17}$, los servicios empresariales, en algunos casos, son desarrollados por parientes o allegados de los dueños de la microempresa principal $^{18}$. Por ejemplo, Tito Mauri y Rossy War, de la empresa Fama Records, tercerizan todos los servicios que no están relacionados con su core business - las presentaciones de Rossy-, en la modalidad de outsourcing ${ }^{19}$.

Cabe señalar que Cuesta y Alonso reflexionan sobre la empresa virtual como alternativa y sostienen que será una necesidad en las siguientes décadas del siglo XxI. El concepto de empresa virtual fue desarrollado por Mintzberg en la década de los 70

15 Persona que labora para entidades o empresas de manera independiente. El pago que recibe —en algunos casos, por honorarios - es pactado con la institución a la que ofrece su trabajo o servicio para cada caso particular.

Cfr. Acosta 2015: 11-12.

17 El movimiento musical chichero, desarrollado por las promotoras de música chicha, es una fusión de los ritmos tropicales y de la música andina. «Por música chicha no solo entendemos la cumbia 'ahuainada', sino también sus variedades contemporáneas, como la tecnocumbia, la cumbia norteña y de la selva. Asimismo, hemos incluido las variedades de huaino jaranero y con arpa (...)» (Bailón y Nicoli, 2010: 13).

19 Conocido también como tercerización o subcontratación. Es cuando una empresa delega la producción de una parte de los bienes y servicios que ofrece a otra empresa, asumiendo que la ofrecerán en el momento apropiado con la calidad exigida. 
y Peter Drucker la teoriza en la década de los 80. Handy, en el año 1995, bautiza a la organización de trébol, mencionada anteriormente, como una empresa flexible y virtual, en la que solamente el $20 \%$ de las actividades, según él, tienen que ver con el core business del negocio, todo lo demás se hace por outsourcing ${ }^{20}$.

\subsection{CARACTERÍSTICAS DE LOS ADMINISTRADORES MUSICALES}

La organización de instituciones musicales se caracteriza porque sus administradores presentan características propias que, aunque no necesariamente se restringen a los negocios musicales en particular, tienen en común los negocios basados en lo cultural. Estas características, relacionadas con nuestra realidad peruana, se mencionan a continuación:

- El administrador eficiente y eficaz debe tener mucha experiencia en el campo musical, con conocimientos de administración, pero mucha intuición y percepción del entorno. Debe estar al día en la digitalización y tener apertura hacia lo multicultural.

- El administrador musical integral debe tener un amplio bagaje musical, conocer que las creaciones musicales y todo negocio de este rubro está influenciado por el marketing. Se requiere innovación, funding ${ }^{21}$, con una clara visión de benchmarketing ${ }^{22}$.

- El administrador de pequeñas empresas. Como los negocios musicales, pequeños en su mayoría, no tienen administradores netos, la organización debe ser flexible y creativa, para luego crecer y desarrollar algunos niveles tácticos y estratégicos.

- La administración de instituciones musicales públicas presenta problemas burocráticos, como la generación de altos costos al fisco, y puede no contribuir con el desarrollo de las industrias culturales.

- Los administradores de negocios culturales están muy influenciados por los aspectos relacionados con valores, creencias y, en general, por la cultura del entorno específico en el que se manejan.

20 Cfr. Cuesta y Alonso 2011: 264-266.

21 Funding es la búsqueda de recursos económicos y financieros para desarrollar los negocios, en este caso, los musicales.

22 Benchmarking es la técnica o estrategia de buscar las mejores prácticas y copiar total o parte de ellas, con la aplicación al entorno de cada caso. 
- Los administradores financieros, o aquellos administradores que ejercen funciones financieras en negocios musicales, en la mayoría de los casos, se basan en la teoría administrativa y en las finanzas como las de cualquier empresa de otro sector.

\subsection{ANÁLISIS DE LOS CAMBIOS EN EL TIEMPO}

La mayoría de los autores, tanto en el Perú como en el mundo, al explicar que la industria musical llegó antes que la era digital, considera a la primera de ellas como elemento organizacional por excelencia, representativa en el sector ${ }^{23}{ }^{24}$. En el mundo, desde que Edison desarrolló el fonógrafo en 1877 (10 años después, Emile Berliner lo patentó y se introdujo el primer fonógrafo que se vendió en el mercado en 1906 por la compañía Victor RCA), la industria discográfica ha cambiado vertiginosamente. A finales de la década de 1940, aparecieron los discos de 33 y 45 RPM en el mercado mundial. En 1982, se lanzaron las grabaciones en formato CD. Luego, Apple, planteó un hito importante; lanzó el iPod en el 2001 y el streaming comenzó a ser utilizado en el 2007 para la comercialización musical ${ }^{25}$. En el Perú, la industria musical se desarrolló con algún retraso a la par que la industria mundial, con características similares, pero con niveles de envergadura mucho menores.

Consideramos que esto es una simplificación válida para explicar la organización predigital de la industria musical. Sin embargo, en el Perú, las organizaciones radiales también son dignas de mencionarse como representativas. La industria de la radiodifusión sonora en el Perú tiene un crecimiento importante a partir de la década de 1990, y en la época predigital es uno de los motores de la industria discográfica.

Byrne, Fitterman y algunos autores también plantean que las organizaciones de negocios musicales relacionadas con la publicidad (empresas productoras de jingles), intérpretes, compositores y las organizaciones que los agrupan, entre otros, son parte de la industria musical ${ }^{26}$. En este caso, podríamos afirmar que las organizaciones dis-

23 Cfr. Instituto de Investigación de la Escuela Profesional de Turismo y Hotelería de la Universidad de San Martín de Porres 2005: 119.

24 Cfr. Byrne 2012: 81.

25 Cfr. Wikström 2013: 66.

26 Cfr. Instituto de Investigación de la Escuela Profesional de Turismo y Hotelería de la Universidad de San Martín de Porres 2005: 120. 
cográficas y radiales se caracterizaron por tener grandes aparatos organizativos que respondían a sus necesidades económicas, financieras, de marketing y de producción de los bienes o servicios.

Con el advenimiento de la era digital en la industria musical, la organización está asumiendo grandes cambios; por ello, es importante analizar, en primer lugar, la velocidad con la que aparecen últimamente. Un artículo publicado por $\mathrm{PwC}^{28}$ justifica gráficamente esta rapidez en función de los cambios en la composición de los ingresos provenientes de las empresas discográficas en relación con sus productos principales, proyectados del 2014 al 2019 en el mundo ${ }^{29}$.

\section{Gráfico 1.1 Variación de los ingresos de formatos musicales 2014-2019 en miles de millones}

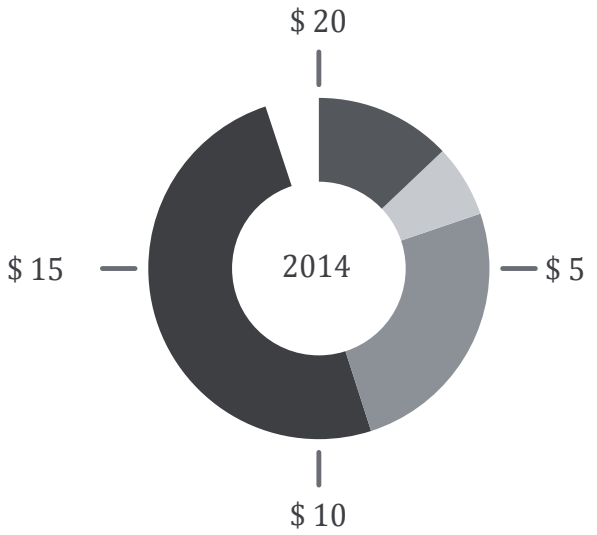

Streaming
Música Movil

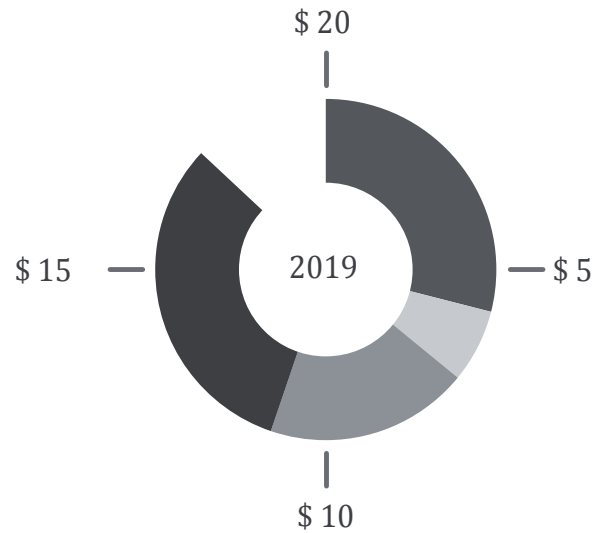

Descargas
Formato físico

Adaptado de Price Waterhouse Coopers.

28 Más conocida como una de las más grandes consultoras empresariales en el mundo, anteriormente llamada Price Waterhouse y Coopers \& Lybrand.

29 Cfr. Navas 2015a. 
En el periodo antes mencionado, los ingresos provenientes de la música streaming $^{30}$ en formato digital son mayores en comparación con los ingresos derivados de la música streaming en formato físico (discos); los ingresos provenientes de la música de los teléfonos celulares se mantienen. La música por descarga disminuye ligeramente entre el 2014 al 2019. Estos datos nos permiten llegar a la conclusión de que el streaming será la mayor forma de adquirir música a fines de la segunda década del segundo milenio. Cabe señalar que los ingresos derivados de la música de los teléfonos celulares no cambiará proporcionalmente en porcentaje hasta el 2019.

El primer impacto en la organización con el paso de la era predigital a la era digital está relacionado con las funciones clásicas administrativas de la empresa. La producción de bienes y servicios, distribución, comercialización, promoción, manejo de los derechos de autor y conexos, entre las principales funciones, cambiarán en la medida que los formatos digitales manejan gran cantidad de información. Por otro lado, los formatos simplifican el uso de los equipos tecnológicos, por su envergadura física, su ubicación y por la posibilidad de usar, con mucha más flexibilidad, la estructura de la organización, en la medida que se puede virtualizar y hacer outsourcing con mayor facilidad. Un ejemplo de lo explicado anteriormente es el caso de Andrés Landavere $^{31}$ en el negocio de producción y composición de música para publicidad, llamado jingle. En este libro se explicará cómo este negocio tiene implicancias organizacionales claras que hacen que, en primer lugar, las barreras de entrada se simplifiquen, los equipos tecnólogicos se reduzcan, en tamaño y costo, y que aumente la competencia, haciendo que este negocio, en la actualdiad, sea más eficiente, el cual también podría ser más eficaz si se hace por outsourcing desde un espacio físico muy reducido, con una organización casi individualizada.

Otro impacto en la organización es el relacionado con el marketing en todas sus facetas, desde las ventas, promoción, distribución y, en general, su virtualización. Actualmente, se puede afirmar que la empresa, para hacer marketing, está conectada con algún usuario de cualquier parte del mundo, las 24 horas del día durante los siete días de la semana, los 365 días del año. Por ello, la estructura organizativa ha ido modi-

30 Streaming se refiere a toda música reproducida por medio de una plataforma digital (Spotify, iTunes), de manera continua y sin interrupciones, distribuida de manera gratuita o a cambio de un pago con plan tarifario. Su ganancia depende de las reproducciones que se generan al usar cualquiera de las plataformas virtuales.

31 Productor de música para publicidad, músico y compositor de rock. Se detallará su caso en el capítulo 10 de la segunda parte de este libro. 
ficándose con el paso del tiempo, a tal punto de necesitar, en la actualidad, de un community manager que pueda realizar dicha labor ${ }^{32}$.

En general, en las áreas de marketing se ha hecho más sofisticado el sondeo de mercado y la toma de decisiones relacionados con el mercadeo, sobre todo porque ahora se cuenta con información más subjetiva y cualitativa que ha conllevado a la adquisición de máquinas y equipos para procesar información; por ello, se ha tenido que reducir personal. Estas áreas administrativas ahora requieren de mayor análisis para responder al mercado en la medida que todos compiten en un mundo más informado. Por otro lado, el uso de motores de búsqueda, la publicidad gráfica orientada, los anuncios en video y medios enriquecidos en línea ${ }^{33}$ ha ido en aumento, lo cual implica áreas plenamente relacionadas con este particular y con la producción de material para ello.

Las organizaciones de las empresas han tenido que asumir la globalización como parte de su entorno, con mercados globales o nacionales, porque en todos los casos compiten en un ambiente donde todas las empresas y marcas están presentes. Un ejemplo de la importancia de los medios electrónicos es el que se da en las grandes corporaciones radiales a nivel nacional; por ejemplo, Radio Programas del Perú (RPP) y Corporación Radial del Perú (CRP). Estas instituciones han tenido que adaptar su organización y crear páginas web, aplicaciones para celulares, cuentas en redes sociales tales como Facebook y Twitter, entre otras. Por otro lado, también han reforzado la parte organizacional de investigación de mercado, con herramientas tecnológicas de punta, para ser más competitivas.

Otro aspecto importante es la influencia en los tipos de productos que se han desarrollado en las diferentes industrias culturales, quizás la más representativa es la, antes mencionada, industria discográfica. En el mundo, y en el Perú quizás con un poco menos de énfasis, se presenta el tránsito desde los formatos tangibles hasta la música individualizada del streaming. El gráfico 1.2 muestra dicha evolución planteada en el libro Introduction to the music industry ${ }^{34}$, que, en cierto modo, es congruente con lo planteado en el gráfico 1.1:

32 Referido a la persona o área que se encarga de todas las relaciones de la empresa por internet, tales como manejo de redes sociales, marketing online y plataformas virtuales, entre las aplicaciones más importantes.

33 Cfr. Laudon y Guercio 2014: vii.

34 Cfr. Fitterman 2013: 41. 


\section{Gráfico 1.2 La evolución del formato de música grabada}

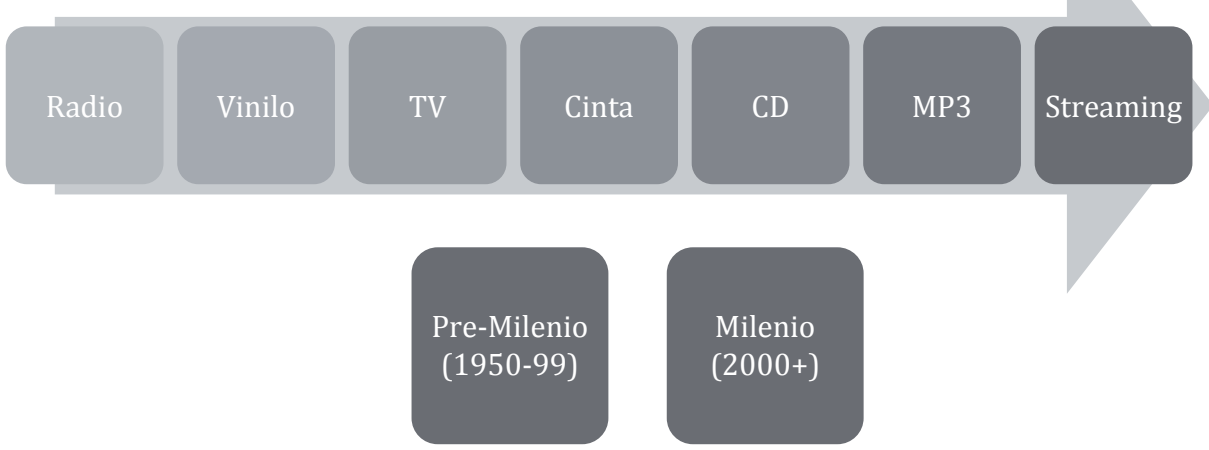

Fuente: Fitterman 2013

Este esquema explica con detalle los cambios que se han dado en el avance de los formatos de reproducción musical más usados en cada época, a las que Fitterman llama premilenio y milenio. Este gráfico explica el panorama de la reproducción musical fonográfica, puntualizando los cambios que se han dado en el avance de los formatos de reproducción musical más usados en cada época — desde su reproducción en radio y los vinilos hasta la reproducción vía streaming - a las que Fitterman llama premilenio y milenio. Podríamos decir que existe un sistema de elección individualizada por excelencia, ya que conforme avanzan las décadas, el usuario tiene diversos canales y formas de escucha.

\subsection{LA CADENA DE VALOR ENTRE LA INDUSTRIA MUSICAL Y SU EVOLUCIÓN EN EL TIEMPO}

Como se ha podido observar, la industria musical y, por lo tanto, sus ingresos, ha ido evolucionando con el paso del tiempo, haciendo que la cadena de valor se adapte según los cambios tenológicos. No solo se han realizado cambios en el formato y la industria musical, sino también en relación con su administración y organización empresarial en esencia, de acuerdo con los cambios de los nuevos enfoques administrativos, relacionados, básicamente, con la globalización y el avance tecnológico. 
Fitterman presenta un gráfico adaptado de Graham ${ }^{35}$ sobre una descripción ilustrada de la cadena de valor en la industria discográfica que existió antes del 1999, a la que llamó etapa premilenial, la cual he relacionado, haciendo una simplificación, con la etapa predigital. El gráfico 1.3 presenta al artista musical que ha sido controlado por las restricciones: impuestas por los sistemas de grabación de los formatos físicos. Cabe señalar que la búsqueda de artistas con talento se convirtió en una prioridad para las empresas discográficas; por ello, el artista pasó a ser parte de la cadena de valor de una compañía discográfica, otorgando sus derechos a dichas empresas discográficas, para así poder grabar, distribuir su música y llegar al mercado masivo ${ }^{36}$.

\section{Gráfico 1.3 La cadena de suministro en la música tradicional}

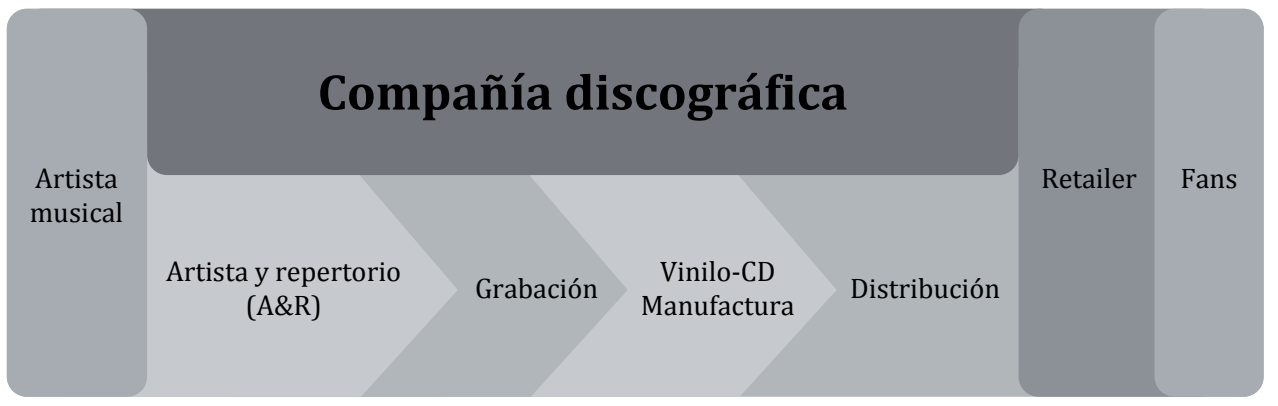

Fuente: Fitterman 2013.

En la época premilenial, las características del producto musical físico - el disco compacto - eran el artista y su imagen, su expresión musical, la propiedad intelectual y el formato físico del producto. Sin embargo, en el siguiente milenio, llamado millenium por Graham, la tecnología digital impacta en la distribución física tradicional de la músca y, en general, en el negocio musical, de manera que el control de la producción y las barreras de distribución no tienen las limitaciones anteriores de la cadena del valor para el artista, los cuales, gracias a la tecnología, ahora pueden operar independientemente y relacionarse directamente con el público consumidor y este, a su vez, tiene más opciones de elegir ${ }^{37}$. 
Como consecuencia de esto, las organizaciones musicales han sufrido una mutación que les ha permitido ser pequeñas en algunos casos, virtuales en otros y, en todo caso, adaptarse a esta época. El gráfico 1.4 muestra la cadena de valor de la industria discográfica después del milenio.

\section{Gráfico 1.4 La cadena de valor de la distribución musical del milenio}

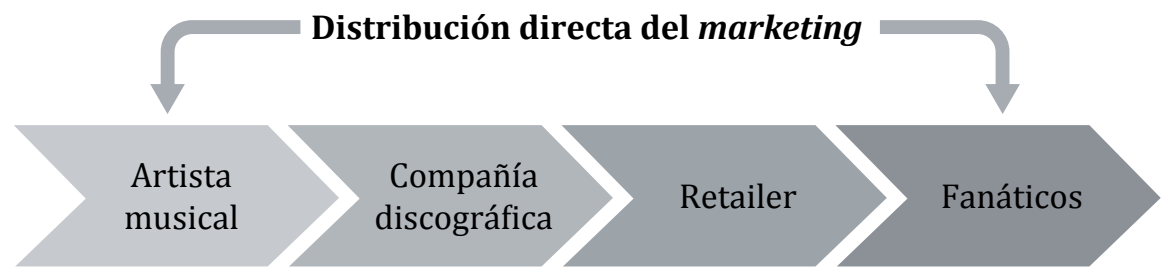

Fuente: Fitterman 2013.

Este capítulo nos demuestra que, si bien las industrias musicales presentan características similares a las de una organización de cualquier tipo, en términos generales, la industria musical presenta una particularidad: está relacionada con la creatividad, además está adquiriendo cada vez más importancia en el Perú y expandiéndose en la industria digital.

También es importante plantear el hecho de que gran parte de la organización de la industria musical está basada en sistemas intermitentes unitarios, también llamados proyectos. Un proyecto es un producto musical que se desarrolla a medida que se elabora y brinda un valor agregado, diferente, con respecto al anterior. Esto implica, por ejemplo, que si bien es cierto los eventos musicales presentan características similares, difieren en sus características específicas. Esto también se ve explícito, por ejemplo, en los lanzamientos de discos, diferentes entre ellos; la elaboración de guitarras, eléctrica o acústica, a pedido, etcétera; o la realización de una gira de un grupo musical, folclórico o de cualquier otro género. Para ampliar la explicación, consideremos el caso de las producciones musicales; en todas ellas se presentan diferentes etapas - preproducción, grabación, edición, posproducción- y se utilizarán diferentes recursos humanos; en algunos casos, durante la realización del proyecto musical se necesitará un compositor y en la grabación será necesario contratar a cinco músicos sesionistas, en otro proyecto musical, quizás no se necesitará al compositor y será necesario solo un músico de sesión. 
Para poder revisar todo el contenido de esta edición, visite nuestra tienda virtual.

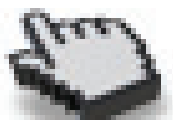

NEGOCIOS

$\varphi$

MUSICALES

¿SE PUEDE VIVIR DEL

ARTE EN EL PERÚ?

Gino Foppiano

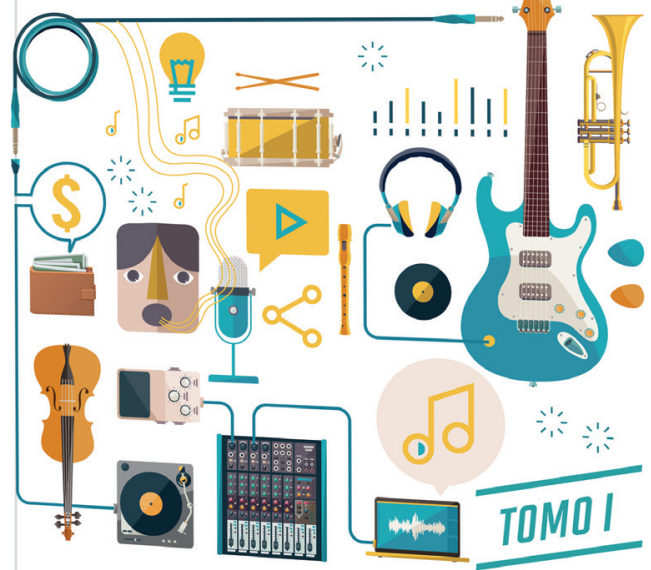

